\title{
CONTROLE DO AMADURECIMENTO DE GOIABAS 'KUMAGAI' TRATADAS COM 1-METILCICLOPROPENO'
}

\author{
THALES SANDOVAL CERQUEIRA², ANGELO PEDRO JACOMINO ${ }^{3}$, \\ FABIANA FUMI SASAKI ${ }^{4}$, LILIAN AMORIM ${ }^{5}$
}

RESUMO-A alta perecibilidade da goiaba é o principal problema enfrentado pelos produtores na comercialização da fruta in natura, tanto no mercado nacional, como no internacional. O 1-metilciclopropeno (1-MCP) é um regulador vegetal conhecido como bloqueador da ação do etileno, empregado para retardar o amadurecimento de frutos e estender sua vida útil. Assim, o presente trabalho teve por objetivo determinar os efeitos da aplicação do regulador vegetal 1-MCP sobre a qualidade pós-colheita de goiabas 'Kumagai'. As goiabas foram colhidas quando a cor da casca começou a mudar de verde-escura para verde-clara, tendo como base os índices de firmeza $(\mathrm{N})$ e cor da casca $\left({ }^{\circ} \mathrm{h}\right)$ de $85 \mathrm{~N}$ e $117^{\circ} \mathrm{h}$, respectivamente, em lotes uniformes, sem defeitos. Os frutos foram expostos ao 1-MCP durante 3 horas, em câmara hermética, nas concentrações de $0 ; 100 ; 300$ e 900 nL.L $\mathrm{L}^{-1}$ e armazenadas a $22 \pm 2{ }^{\circ} \mathrm{C}$ e $80-85 \%$ UR durante 12 dias. O regulador vegetal retardou a perda da cor verde da casca e da firmeza da polpa, bem como o incremento dos teores de ácido ascórbico e de sólidos solúveis, entretanto não alterou a perda de massa, a acidez titulável e a incidência de podridões. A atividade respiratória e a produção de etileno também foram influenciadas pelo 1-MCP, tendo atingido os menores valores ao empregar a maior concentração deste regulador vegetal. A aplicação de 1-MCP, nas concentrações de 300 a $900 \mathrm{~nL} . \mathrm{L}^{-1}$, durante 3 horas, retarda o amadurecimento de goiabas 'Kumagai', prolongando sua vida pós-colheita.

Termos para indexação: Regulador vegetal; Psidium guajava; 1-MCP; etileno; respiração.

\section{RIPENING CONTROL OF 'KUMAGAI' GUAVAS SUBMITED TO 1-METHYLCYCLOPROPENE}

\begin{abstract}
The short guava shelf life is the main problem that affects commercialization of fruits, either in national or international markets. The 1-MCP is known as an ethylene blocker. This work was carried out to determine the effects of 1-MCP over attributes of quality of 'Kumagai' guavas. The guavas were harvested with the skin color changing from dark-green to light-green stage, presenting: firmness $(\mathrm{N}) 85$ and skin color $\left(\mathrm{h}^{\circ}\right) 117$, without injuries. Fruits were exposed to $0,100,300,900 \mathrm{~nL} \cdot \mathrm{L}^{-1}$ of 1 -MCP for 3 hours. Later the fruits were kept in room temperature of $22 \pm 2{ }^{\circ} \mathrm{C}$ and $80-90 \% \mathrm{RH}$ for 12 days. The treatments delayed the skin color and firmness changes, and also delayed the increase of ascorbic acid and sugar; the weight loss, titratable acidity and incidence of rots were not affected. The respiratory rate and ethylene production were suppressed reaching the lowest values with the highest concentration of the product. The application of 1-MCP from 300 to 900 nL.L-1 , during 3 hours, extended the shelf life of guavas 'Kumagai'.
\end{abstract}

Index terms: Vegetal regulator; Psidium guajava; 1-MCP; ethylene; respiration.

\section{INTRODUÇÃO}

A goiaba é uma fruta nativa da América tropical e atualmente pode ser encontrada em todas as regiões do Brasil (Choudhury, 2001). É uma fruta muito popular e uma excelente fonte de vitamina $\mathrm{C}$. Os principais fatores depreciadores da qualidade póscolheita de goiabas são a rápida perda da coloração verde da casca, amolecimento excessivo, elevada incidência de podridões, murchamento dos frutos e perda de brilho. $\mathrm{O}$ aumento da vida útil da goiaba em temperatura ambiente é desejável, uma vez que a quase totalidade dos frutos comercializados no Brasil, tanto no atacado quanto no varejo, não está submetidas à refrigeração. A melhor conservação nessas condições pode facilitar o transporte a longas distâncias e ampliar o período de comercialização (Bassetto et al., 2005a).

O fitorregulador etileno está envolvido no amadurecimento e senescência de frutas e hortaliças. Em um determinado estádio da maturação, o etileno presente nos espaços intercelulares liga-se ao seu

'(Trabalho 148-08). Recebido em: 12-06-2008. Aceito para publicação em: 07-04-2009.

${ }^{2}$ Mestre, Escola Superior de Agricultura “Luiz de Queiroz", Depto. de Produção Vegetal, Piracicaba - SP. e-mail: tscerque@esalq.usp.br 3Prof. Associado, Escola Superior de Agricultura "Luiz de Queiroz" - USP, departamento de Produção Vegetal jacomino@esalq.usp.br

${ }^{4}$ Mestre, Escola Superior de Agricultura "Luiz deQueiroz" - USP, departamento de Ciências Biológicas.fsasaki@esalq.usp.br

${ }^{5}$ Profa. Titular, Escola Superior de Agricultura "Luiz deQueiroz" - USP, Depto. de Fitopatologia e Nematologia. liamorim@esalq.usp.br 
receptor na célula e desencadeia uma série de eventos que culminam com o amadurecimento e senescência do fruto (Lelièvre et al., 1997). Partindo deste princípio, o uso de moléculas que impessam a ligação do etileno ao sítio ativo de seu receptor pode reduzir a sua ação e produção autocatalítica, retardando o amadurecimento e a senescência dos frutos.

O 1-metilciclopropeno (1-MCP) é um composto volátil que tem demonstrado ser um potente antagonista da ligação do etileno ao seu sítio ativo na célula, atuando, tanto sobre o etileno endógeno quanto exógeno (Serek et al., 1995). O 1-MCP liga-se ao receptor de etileno irreversivelmente, e o posterior amadurecimento do fruto é devido à formação de novos receptores (Feng et al., 2000). Além de atuar como antagonista na ligação do etileno, o 1-MCP pode também suprimir a produção de etileno e, com isso, retardar o amadurecimento de frutos como o mamão (Jacomino et al., 2002), a goiaba (Bassetto et al., 2002) e o pêssego (Kluge \& Jacomino, 2002), dentre outros. Esse regulador tem sido utilizado com sucesso também na conservação de flores e hortaliças com aumento efetivo na vida útil.

A concentração de 1-MCP necessária para bloquear a ação do etileno varia conforme a espécie, cultivar, estádio de maturação, produção de novos receptores de etileno, tempo e temperatura de exposição (Rupasinghe et al., 2000; Watkins et al., 2000). Quanto maior o tempo de exposição ao produto, menor a concentração necessária para se obter o efeito desejado (Bassetto, 2002), tendo em vista haver interação entre concentração e tempo de exposição. Bassetto et al. (2005b) aplicaram 1-MCP em goiabas 'Pedro Sato' na concentração de 900 nL.L $\mathrm{L}^{-1}$, durante 3 horas, e obtiveram resultados benéficos, semelhantes à aplicação de $100 \mathrm{~nL} . \mathrm{L}^{-1}$, durante 12 horas. Frente à alta perecibilidade da goiaba, o presente trabalho teve como objetivo averiguar os efeitos da aplicação do regulador vegetal 1-Metilciclopropeno (1-MCP) sobre a qualidade pós-colheita de goiabas 'Kumagai', mantidas em condição ambiente.

\section{MATERIAL E MÉTODOS}

Os experimentos foram conduzidos no Laboratório de Pós-Colheita do Departamento de Produção Vegetal da ESALQ-USP. Utilizaram-se goiabas 'Kumagai', provenientes de produtor comercial do município de Campinas-SP. Foram utilizados lotes uniformes, sem defeitos, de goiabas colhidas quando a cor da casca começou a mudar de verde-escura para verde-clara, e tendo como base os índices determinados por Cavalini et al. (2006) para cor da casca ao redor de $117^{\circ} \mathrm{h}$ de ângulo de cor e firmeza da polpa ao redor de $85 \mathrm{~N}$.

Os frutos foram expostos a atmosferas contendo 1-MCP nas concentrações de 0 (controle); 100; 300 e 900 nL.L ${ }^{-1}$, em câmaras herméticas, com capacidade para $186 \mathrm{~L}$, durante 3 horas, a $22 \pm 2{ }^{\circ} \mathrm{C}$. Para obter as concentrações desejadas de 1-MCP, 3 $\mathrm{mL}$ de água deionizada foram adicionados a frascos contendo quantidades predeterminadas do produto comercial SmartFresh (pó molhável, 0,14\% i.a., AgroFresh). Após a adição de água, os frascos foram agitados por aproximadamente 2 minutos, para completa dissolução do produto, e abertos no interior das câmaras, que foram imediatamente fechadas. Após os tratamentos, os frutos foram armazenados a $22 \pm 2{ }^{\circ} \mathrm{C}$ e $80-90 \%$ UR durante 12 dias, e analisados conforme descrito a seguir.

Coloração da casca: determinada com colorímetro Minolta, modelo CR-300, com a seguinte configuração: sistema de cor L C h, iluminante D65 e observador-padrão $2^{\circ}$. Foram tomadas 2 leituras por fruta, em lados opostos de sua região equatorial, e os resultados, expressos em ângulo de cor $\left(\mathrm{h}^{\circ}\right)$, de acordo com McGuirre (1992), com análise realizada diariamente.

Teor de sólidos solúveis (SS): leitura direta em refratômetro marca Atago, modelo Pallete -101, e os resultados, expressos em ${ }^{\circ} \mathrm{Brix}$, com análise realizada a cada 4 dias.

Acidez titulável (AT): determinada de acordo com metodologia descrita por Carvalho et al. (1990), e os resultados, expressos em \% de ácido cítrico na polpa, com análise realizada a cada 4 dias.

Firmeza da polpa: determinada com penetrômetro digital (TR Italy), com ponteira de $8 \mathrm{~mm}$ na região equatorial da fruta, após a retirada da casca, tomando-se duas leituras por fruta. Os resultados foram expressos em Newton, com análise realizada a cada 4 dias.

Teor de ácido ascórbico: determinado por titulometria, de acordo com metodologia descrita por Carvalho et al. (1990), e os resultados, expressos em mg de ácido ascórbico por $100 \mathrm{~g}$ de polpa, com análise realizada a cada 4 dias.

Incidência de podridões: avaliada visualmente, contando-se o número de goiabas com presença de podridões, que continham lesões com diâmetro superior a $0,5 \mathrm{~cm}$. Os resultados foram expressos em porcentagem de goiabas doentes, com análise realizada a cada 4 dias.

Respiração e produção de etileno: as goiabas foram colocadas em frascos de vidro, hermeticamente fechados, com capacidade de $600 \mathrm{~mL}$, e septo de silicone nas tampas. Os frascos foram fechados por 
60 minutos para a coleta das amostras de gás, as quais foram injetadas em cromatógrafo a gás (Thermo Finnigan, Thermoquest GC Trace 2000) com coluna Porapack, metanador e detector de ionização de chama (FID). Os resultados, expressos em ppm de $\mathrm{CO}_{2}$ e de etileno, foram utilizados no cálculo da atividade respiratória e da produção de etileno, respectivamente. No caso do etileno, os fracos permaneceram fechados por 120 minutos, e as amostras foram injetadas em uma via do cromatógrafo, sem metanador. As determinações foram realizadas diariamente. Foram utilizadas 6 repetições de uma goiaba por frasco, para cada tratamento, com análise realizada diariamente.

$\mathrm{O}$ delineamento experimental foi o inteiramente casualizado, em esquema fatorial 4 (doses de 1 -MCP) x 4 (tempos $0 ; 4 ; 8$ e 12 dias) ou 4 (doses de 1 -MCP) x 13 (tempos $0 ; 1 ; 2 ; 3 ; 4 ; 5 ; 6 ; 7 ; 8 ; 9$; $10 ; 11$ e 12 dias), dependendo da variável. Os resultados foram submetidos à análise de variância (teste F), e, em caso de significância, as médias foram comparadas pelo teste de Tukey, ao nível de 5\% de probabilidade.

\section{RESULTADOS E DISCUSSÃO}

A aplicação de 1-MCP reduziu a atividade respiratória das goiabas (Figura 1A). O tratamento com 900 nL.L $\mathrm{L}^{-1}$ de 1 -MCP apresentou a menor produção de $\mathrm{CO}_{2}$ ao longo do armazenamento, com valor de $9,8 \mathrm{mLCO}_{2} \cdot \mathrm{Kg}^{-1} \cdot \mathrm{h}^{-1}$ no décimo segundo dia, diferindo significativamente $(\mathrm{p} \leq 0,05)$ dos demais tratamentos. Bassetto et al. (2005) obtiveram resultado semelhante em goiabas 'Pedro Sato'. O tratamento com 900 nL.L ${ }^{-1}$ de 1-MCP manteve a menor produção de etileno durante o armazenamento em relação ao tratamento-controle (Figura 1B). Uma grande variedade de tecidos vegetais apresenta elevação da atividade respiratória em resposta ao etileno (Chitarra \& Chitarra, 2005). Sendo assim, é esperado que a inibição da ação do etileno via 1-MCP resulte em redução da atividade respiratória.

A retenção da cor verde da casca $\left(\mathrm{h}^{\circ}\right)$ foi tanto maior quanto maior a concentração de 1-MCP (Figura 2A). As goiabas do tratamento-controle apresentaram casca amarela com valor para o ângulo de cor de $94^{\circ}$, diferindo significativamente $(\mathrm{p} \leq 0,05)$ das tratadas com 900 nL.L - $^{-1}$, com valores para o ângulo de cor de $106^{\circ}$ no décimo segundo dia de armazenamento. O aumento da atividade da enzima clorofilase está geralmente associado com a produção e ação do etileno durante o amadurecimento do fruto. Estudos recentes mostram que o 1-MCP reduz a atividade da clorofilase em brócolis (Watkins, 2006) e bloqueia o desverdecimento em laranjas (Porat et al., 1999) e em mamão (Jacomino et al., 2002). Segundo Tucker (1993), a perda da cor verde é devida à quebra da estrutura da molécula de clorofila, envolvendo a atividade da enzima clorofilase.

Em relação ao teor de sólidos solúveis, o menor incremento ocorreu nos tratamentos com 300 nL.L - $^{-1}$ e 900 nL.L - $^{-1}$ de 1-MCP, diferindo dos demais $(\mathrm{p} \leq 0,05)$ ao final do armazenamento. No $12^{\circ}$ dia, o teor de sólidos solúveis nas goiabas sem 1-MCP foi $9,8^{\circ}$ Brix, enquanto aquelas com 900 nL. $\mathrm{L}^{-1}$ apresentavam $8,7^{\circ}$ Brix (Figura 2B). Embora a goiaba seja uma espécie que praticamente não armazena amido, pequenos incrementos no teor de sólidos solúveis (SS) têm sido observados durante o amadurecimento. Segundo Chitarra \& Chitarra (2005), o teor de açúcares usualmente aumenta com o amadurecimento das frutas por meio de processos biossintéticos ou pela degradação de polissacarídeos. O aumento do teor de sólidos solúveis pode ser devido à conversão de polissacarídeos da parede celular em açúcares solúveis. Singh \& Pal (2008) verificaram que, em goiabas 'Safeda', o tratamento com 1-MCP restringiu o aumento de sólidos solúveis para frutas armazenadas a $10^{\circ} \mathrm{C}$, mas para as armazenadas em temperatura ambiente, o teor de sólidos solúveis aumentou, sendo os maiores incrementos para os tratamentos com as maiores concentrações.

Houve aumento significativo nos teores de ácido ascórbico ao longo do armazenamento para todos os tratamentos, sendo este aumento mais acentuado nas frutas não tratadas (Figura 2C). Segundo Esteves et al. (1984), os teores de vitamina $\mathrm{C}$ aumentam durante o amadurecimento de goiabas e diminuem durante a senescência. Bassetto et al. (2005) verificaram que as quantidades de ácido ascórbico não foram influenciadas pelo 1-MCP em goiabas 'Pedro Sato'.

Afirmeza da polpa, no final do armazenamento, foi maior $(p \leq 0,05)$ no tratamento com a maior concentração de 1-MCP, com valor de $58 \mathrm{~N}$ (Figura 2D). As goiabas sem 1-MCP e aquelas tratadas com 100 nL.L - $^{-1}$ apresentaram o mesmo valor de firmeza no $12^{\circ}$ dia $(13 \mathrm{~N})$. As goiabas tratadas com $300 \mathrm{~nL} . \mathrm{L}-1$ assumiram valor intermediário $(36 \mathrm{~N})$ e diferiram dos demais tratamentos. Hofman et al. (2001) observaram que o 1-MCP retardou a perda de firmeza de diversas frutas, como o abacate, que reteve a perda de firmeza por 4,4 dias, manga por 5,1 dias e mamão por 15,6 dias. Bassetto et al. (2005) verificaram que goiabas 'Pedro Sato' tratadas com 900 nL.L ${ }^{-1}$, por três horas, mantiveram a firmeza por oito dias. Em mamão 'Sunrise Solo', Jacomino et al. (2002) verificaram manutenção da firmeza em frutos tratados com concentrações entre 
90 nL.L $\mathrm{L}^{-1}$ e 270 nL.L $\mathrm{L}^{-1}$ por 12 horas. Também Bron et al. (2006) verificaram, em mamão 'Golden', a retenção da firmeza em frutos tratados com 100 nL.L $\mathrm{L}^{-1}$ de 1-MCP.

Lelièvre et al. (1997) apud Kluge \& Jacomino (2002) consideram que o amolecimento dos frutos é um dos processos mais afetados pelo etileno. A firmeza é determinada pela força de coesão entre pectinas. Como no processo de amadurecimento, as enzimas pectinolíticas transformam a pectina insolúvel em solúvel, isto acaba promovendo o amolecimento dos tecidos. Segundo Feng et al. (2000), as atividades da poligalacturonase (PG) e celulase são reduzidas pelo 1-MCP, acarretando em menor perda na firmeza dos vegetais.

A incidência de podridões começou a ser observada a partir do sétimo dia de armazenamento e aumentou à medida que as goiabas amadureceram, independentemente dos tratamentos, atingindo $55 \%$ dos frutos no $12^{\circ}$ dia, nos tratamentos em que receberam o $1-\mathrm{MCP}$ e $70 \%$ no tratamento-controle. Resultados semelhantes foram encontrados por Kluge \& Jacomino (2002) em pêssegos, quando o
1-MCP reduziu o desenvolvimento de podridões nos frutos do estádio verde, mas não em frutos maduros. Blankenship \& Dole (2003) afirmam que o 1-MCP apresenta respostas variadas para diferentes culturas, inibindo distúrbios fisiológicos em algumas culturas, como, por exemplo, escaldadura superficial em maçãs, mas aumentando a incidência ou a severidade de determinadas doenças, como o aumento do apodrecimento em morangos, o qual pode ter sido causado por um menor conteúdo de compostos fenólicos encontrado nos frutos tratados. Os mesmos autores verificaram que, em cenouras, o 1-MCP inibiu a síntese de fitoalexinas e 6-metoximielina, compostos conhecidos como integrantes das defesas contra patógenos dos vegetais, o que poderia facilitar o estabelecimento dos patógenos.

Os tratamentos com 1-MCP não influenciaram no teor de acidez titulável, sendo que todos os tratamentos apresentavam valores em torno de $0,75 \mathrm{mg}$ de ácido cítrico. $100 \mathrm{~g}$ de polpa ${ }^{-1}$ no final armazenamento, assim como a perda de massa que atingiu valores acima de $15 \%$ para todos os tratamentos (dados não apresentados).
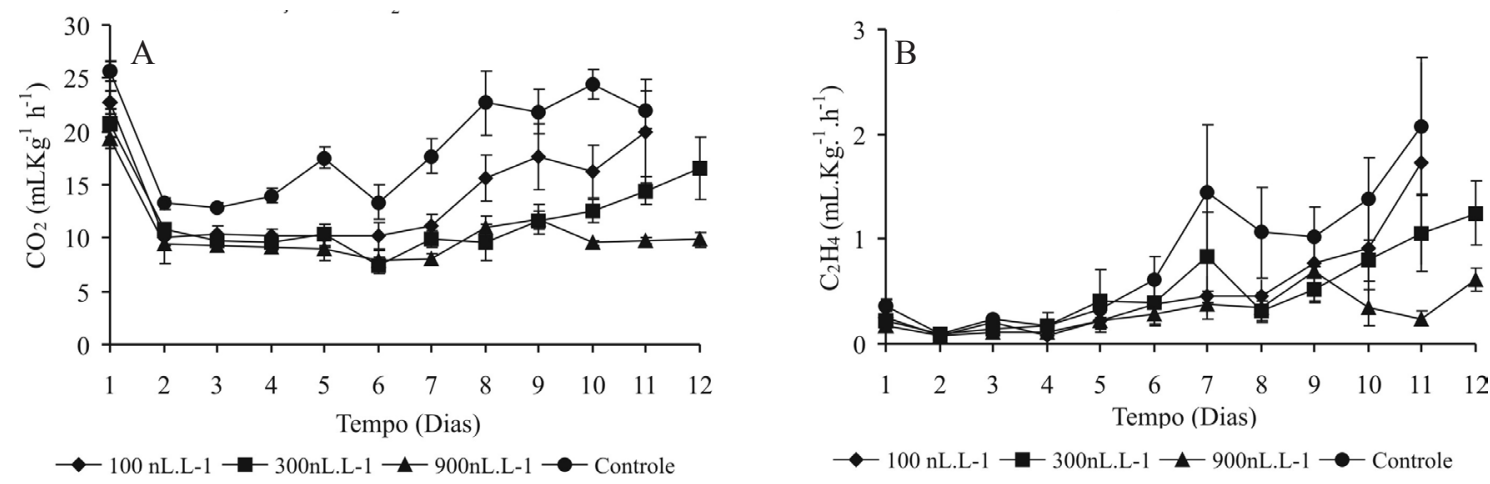

FIGURA 1 - Produção de $\mathrm{CO}_{2}$ (A) e etileno (B) de goiabas 'Kumagai' tratadas com 1-MCP e armazenadas a $22 \pm 2{ }^{\circ} \mathrm{C}$. Barras verticais representam o erro-padrão das médias. 

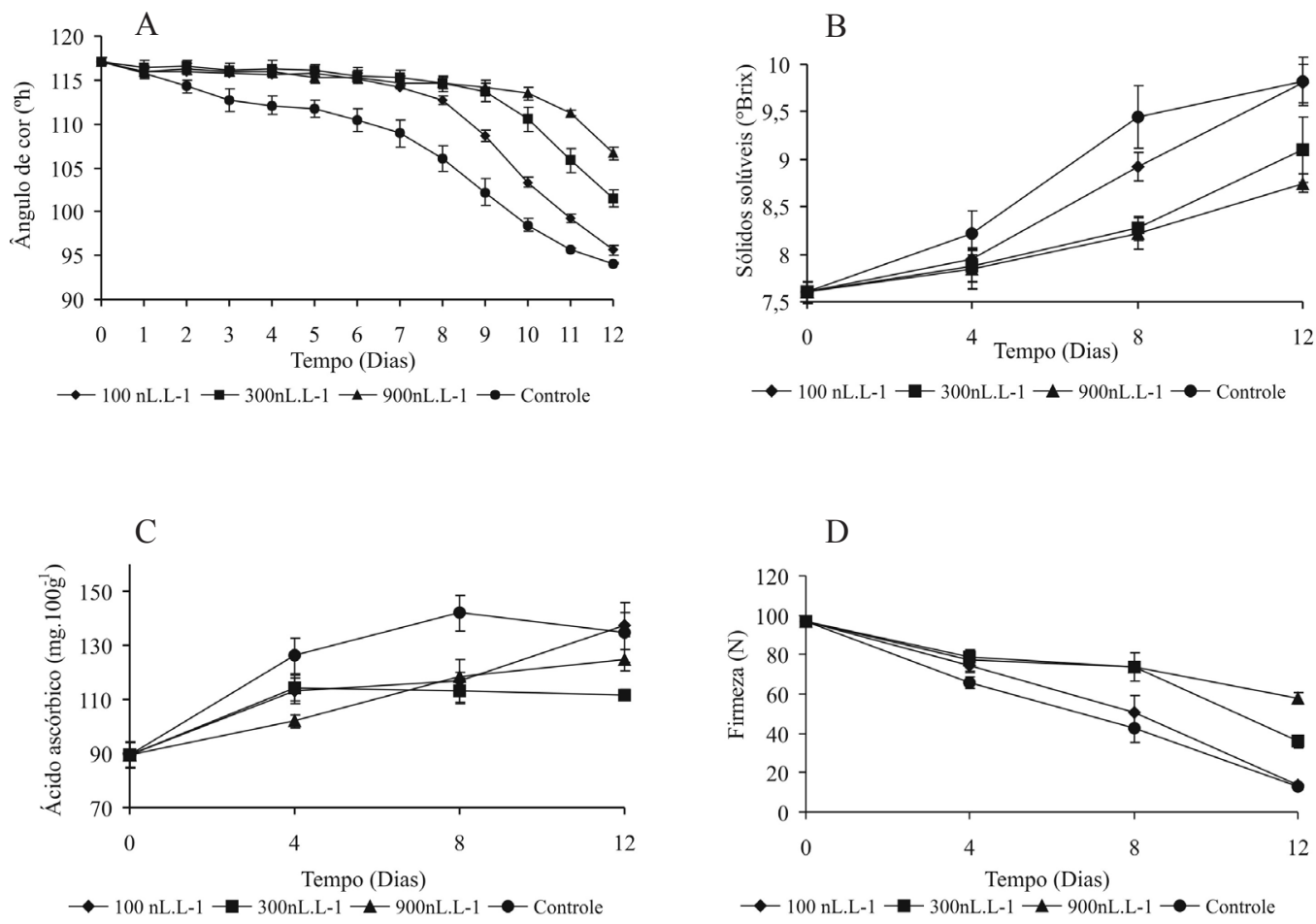

FIGURA 2 - Cor da casca (A); sólidos solúveis (B); ácido ascórbico (C); firmeza (D) de goiabas 'Kumagai' tratadas com 1-MCP e armazenadas a $22 \pm 2{ }^{\circ} \mathrm{C}$. Barras verticais representam o erro-padrão das médias.

\section{CONCLUSÃO}

O regulador vegetal 1-metilciclopropeno retarda o amadurecimento de goiabas 'Kumagai', promovendo como principais efeitos a redução da perda da firmeza e da cor verde da casca. Assim, concentrações de 1-MCP de 300 a 900 nL.L-1 podem ser utilizadas no tempo de exposição de 3 horas, visando a estender a vida pós-colheita desse fruto.

\section{REFERÊNCIAS}

BASSETTO, E. Conservação de goiabas 'Pedro Sato' tratadas com 1-metilciclopropeno: concentrações e tempos de exposição. $2002.71 \mathrm{f}$. Dissertação (Mestrado em Fitotecnia) - Escola Superior de Agricultura “Luiz de Queiroz”, Universidade de São Paulo, Piracicaba, 2002.

BASSETTO, E.; JACOMINO, A.P.; PINHEIRO, A.L. Conservation of 'Pedro Sato' guavas under treatment with 1-methylcyclopropene, Pesquisa Agropecuária Brasileira, Brasília, v.40, n. 5, p. 433-440, 2005a.
BASSETTO, E.; JACOMINO, A.P.; PINHEIRO, A.L.; KLUGE, R.A. Delay of ripening of 'Pedro Sato' guava with 1- methylcycloproprene, Postharvest Biology and Technology, Wageningen, v. 35, n. 3, p. 303-308, 2005 b.

BASSETTO, E.; SESSO, T.M.; JACOMINO, A.P.; KLUGE, R.A. Efeito de 1-MCP e prochloraz na conservação de goiabas 'Pedro Sato'. Revista Iberoamericana de Tecnologia Postcosecha, Sonora, v.4, n. 2, p.122-127, 2002.

BLANKENSHIP, S.M.; DOLE, J.M. 1-Methylcyclopropene: a review. Postharvest Biology and Technology, Amsterdam, v.28, n.1, p.1-25, 2003.

BRON, I. U.; JACOMINO, A. P.; PINHEIRO, A. L. Influência do estádio de amadurecimento em atributos físicos e químicos do mamão 'Golden' tratado com 1-metilciclopropeno. Bragantia, Campinas, v.65, n.4, p. 553-558, 2006.

CARVALHO, C.R.L.; MANTOVANI, D.M.B.; CARVALHO, P.R.N.; MORAES, R.M.M. Análises químicas de alimentos. Campinas: ITAL, 1990. $121 p$. Manual técnico 
CAVALINI, F.C.; JACOMINO, A.P.; LOCHOSKI, M.A.; KLUGE, R.A.; ORTEGA, E.M.M. Maturity indexes for 'Kumagai' and 'Paluma' guavas. Revista Brasileira de Fruticultura, Jaboticabal, v. 28, n. 2, p. 176-179, 2006.

CHITARRA, M.I.F.; CHITARRA, A.B. Pós-colheita de frutas e hortaliças: fisiologia e manuseio. 2. ed. Lavras: UFLA, 2005. 783p.

CHOUDHURY, M. M. Goiaba: pós-colheita. Petrolina: Embrapa Semi-árido, 2001. 45p.

ESTEVES, M.T. da C.; CARVALHO, V.D. de; CHITARRA, M.F.I.; CHITARRA, A.B.; PAULA, M.B. de. Caracterização dos frutos de seis cultivares de goiabeira (Psidium guajava L.) na maturação. I. Determinações físicas e químicas. In: CONGRESSO BRASILEIRO DE FRUTICULTURA, 7., 1983, Florianópolis. Anais... Florianópolis: SBF, 1984. v.2, p.477-489.

FENG, X.; APELBAUM, A.; SISLER, E.C.; GOREN, R. Control of ethylene responses in avocado fruit with 1- methylcyclopropene. Postharvest Biology and Technology, Amsterdam, v. 20, n. 2, p. 143-150, 2000.

HOFMAN, P.J.; JOBIN-DÉCOR, M.; MEIBURG, G.F.; MACNISH, A.J.; JOYCE, D.C. Ripening and quality responses of avocado, custard apple, mango and papaya fruit to 1-methyciclopropene. Australian Journal of Experiment Agricuture, Victoria, v. 41, n. 4 , p. 567-573, 2001.

JACOMINO, A.P.; KLUGE, R.A; BRACKMANN, A.; CASTRO, P. R. de C. Amadurecimento e senescência de mamão com 1-metilciclopropeno. Scientia Agricola, Piracicaba, v. 59, n. 2, p. 303-308, 2002.

KLUGE, R. A.; JACOMINO, A. P. Shelf life of peaches treated with 1-methylciclopropene. Sciencia Agricola, Piracicaba, v. 59, n. 1, p. 69-72, 2002.

LELIÉVRE, J.M.; LATCHÉ, A.; JONES, B.; BOUZAYEN, M.; PECH, J.C. Ethylene and fruit ripening, Physiologia Plantarum, Copenhagen, v. 101, n. 4, p. 727-739, 1997.
McGUIRRE, R.G. Reporting of objective color measurements. HortScience, Alexandria, v.27, n. 12, p.1254-1255, 1992.

PORAT, R.; WEISS, B.; COHEN, L.; DAUS, A.; GOREN, R.; DROBY, S. Effects of ethylene and 1methylcyclopropene on the postharvest quatlities of 'Shamouti' orange. Postharvest Biology and Technology, Amsterdam, v. 15, n. 2, p.155-163, 1999.

RUPASINGHE, H.P.V.; MURR, D.P.; PALYATH, G.; DEELL, J.R. Suppression of $\alpha$ - farnesene synthesis in 'Delicious' apples by aminoeth-oxyvinylglycine (AVG) and 1- methycyclopropene (1- MCP). Physiology and Molecular Biology in Plants, New York, v. 6, n. 2, p. 195-198, 2000.

SEREK, M.; SISLER, E. C.; REID, M.S. 1- methylcyclopropene, a novel gaseous inhibitor of ethylene action, improves the life of fruit, cut flowers and potted plants. Acta Horticulturae, Kyoto, v. 1, n. 394, p. 337-345, 1995.

SINGH, S.P.; PAL, R.K. Response of climacteric-type guava (Psidium guajava L.) to postharvest treatment with 1-MCP, Postharvest Biology and Technology, Amsterdam, v.47, n.3, p. 307-314, 2008

TUCKER, G. A. Introduction. In: SEYMOUR, G. B.; TAYLOR, J. E.; TUCKER, G. A. Biochemestry of fruit ripening. London: Chapmal \& Hall, 1993. p. 2-51.

WATKINS, C.B. The use of 1- methylcyclopropene (1- MCP) on fruits and vegetables. Biotechnology Advances, Atlanta, v. 24, n. 4, p. 389-409, 2006.

WATKINS, C.B.; NOCK, J.F.; WHITAKER, B.D. Responses of early, mid and late season apple cultivars to postharvest application of 1-methylcyclopropene (1-MCP) under air and controlled atmosphere storage conditions. Postharvest Biology and Technology, Amsterdam, v. 19, n. 1, p. 17-32, 2000. 